\title{
STRUCTURAL PERFORMANCE OF BOLTLESS BEAM END CONNECTORS
}

\author{
S.N.R. Shah ${ }^{1}$, N.H. Ramli Sulong ${ }^{2, *}$, R. Khan $^{3}$ and M.Z. Jumaat ${ }^{2}$ \\ ${ }^{1}$ Civil Engineering Department, Mehran University of Engineering \&Technology, SZAB Campus, Khairpur, Pakistan \\ ${ }^{2}$ Department of Civil Engineering, University of Malaya, 50603, Kuala Lumpur, Malaysia \\ ${ }^{3}$ Mechanical Engineering Department, Al-Imam Muhammad Ibn Saud Islamic University, \\ Riyadh 11432, Kingdom of Saudi Arabia \\ *(Corresponding author: E-mail: hafizah_ramli@um.edu.my)
}

Received: 9 May 2016; Revised: 23 July 2016; Accepted: 13 August 2016

\begin{abstract}
This study examines the structural performance of beam end connectors used as connection device in semi-rigid boltless beam-to-column connections (BCCs) in steel pallet racks (SPRs). A total of six types of specimens were tested which were distinguished by the three different types of beam end connector (BEC) thicknesses and two different numbers of tabs in the (BEC). The experimental testing was performed using double-cantilever test method and the moment-rotation (M- $\theta$ ) behavior of the connections and key failure modes were evaluated. The influence of variation in the thickness and the number of tabs of the BEC on the behavior of connection was also investigated. Increased connector thickness enabled the connector tabs to sustain higher failure moment. The findings showed that by varying the geometrical properties, the stiffness of the connection was affected at a higher rate as compared to the strength of the connection. A non-linear three dimensional (3D) finite element (FE) model was developed to simulate the experimental investigations. The FE model showed a close agreement with experimental results.
\end{abstract}

Keywords: steel pallet racks, beam end connector, moment-rotation behavior, double-cantilever test, down-aisle direction

DOI: $10.18057 /$ IJASC.2017.13.2.4

\section{INTRODUCTION}

Steel storage racks are the most widely used cold-formed steel (CFS) structures for the storage of multitude of goods in the warehouses and supermarkets [1]. These lightweight structures can carry live loads much heavier than their self-weight [2]. The most commonly used type of storage racks is 'steel pallet racks (SPRs)'. The SPRs satisfactorily solve the storage problems when the space available to store the goods is comparatively less sufficient to the volume of items. These racks require a ready re-adjustment of the members depending upon the storage requirement [1]. Despite a variety in the manufacturing of steel storage racks, the main configuration of these structures is classified into two major directions, namely, the cross-aisle direction and down-aisle direction. The cross-aisle direction is braced with struts whereas, bracing is avoided in the down-aisle direction and the stability of the frame is governed by the beam-to-column connections (BCCs). The bracing in cross-aisle direction starts generally at $160 \mathrm{~mm}$ from the bottom of the column. The bracing is connected to the column using bolts and nuts. For horizontal bracing to column, a brace spacer is fitted over the bolt to locate the bracing against the inside flange of the column. Standard base plates are used with anchor bolts for floor-to-column connection.

As a consequence of its constructional design, a storage rack differs very much from a traditional steel framework. For instance, the columns used in storage racks have pre-designed perforations, depending on an optimal pitch, in their cross-section. The column of a rack frame is a vertical member subjected to compressive forces parallel to their longitudinal axes [3]. The perforated columns used in SPRs are thin shell elements. The thickness of these columns normally varies 
between $1.8 \mathrm{~mm}$ and $3.0 \mathrm{~mm}$. Perforations in columns reduce their cross-sectional area and make them vulnerable for local and/or distortional buckling [4]. A global buckling of the structure may also happen if these columns are not properly designed. The other unique feature of SPRs are the unique boltless connections used as BCCs in these structures [5]. These boltless connections are considered semi-rigid connections in nature [2]. By contrast to the common structural steel connections where bolts or welds are used for joining the beams and columns, these structures utilized a connection device namely the 'beam end connector' (BEC), which is welded at the end of pallet beam and its stiffness supports the bending capacity of the pallet beam. Unique types of hooks are punched inside the BEC which are engaged with column perforations in a special manner to establish the BCCs [6] and allowed free to rotate. A safety lock must be fully inserted into every BEC. If installed correctly, the safety lock will be positioned vertically, with long leg pointing downwards. Once the end connector is secured with the safety locks, the beam can resist an upward force. This helps the BEC to stay in desired position under the accidental impact of fork lift truck when lifting the pallets [6]. Figure 1 shows a typical boltless SPR BCC.

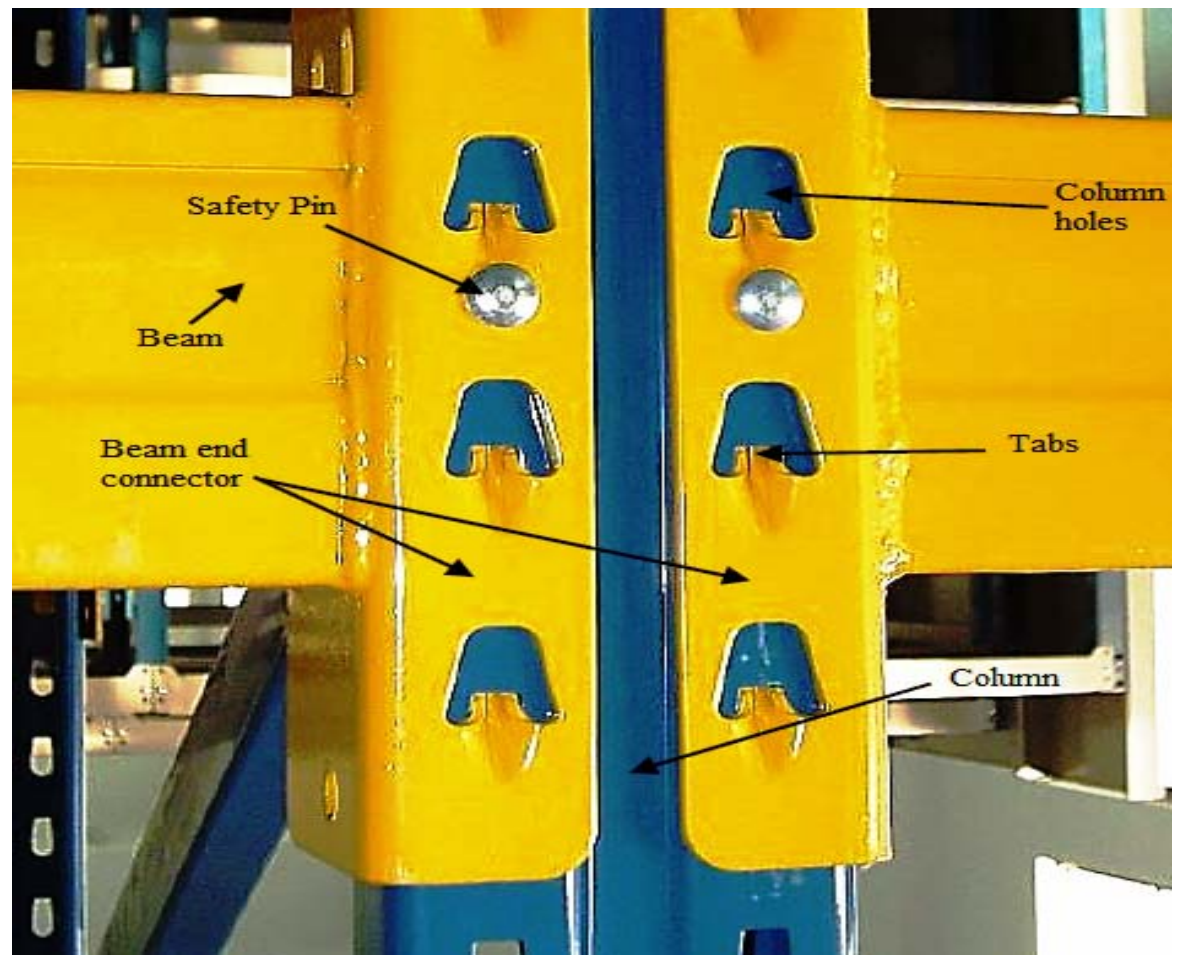

Figure 1. Typical SPR BCC

Despite the availability of several studies available on the behavior of traditional steel connections [7-10], the studies discussing the behavior of SPR BCCs are rare. Being not similar to common building steel connections, the difference in geometry of the BECs available in the market does not allow a generalized global analytical model. This motivated the researchers to predict the structural behavior of SPR BCCs through experimental testing and numerical modelling. Markazi et al. [11] tested different types of connectors using simple cantilever method and declared the influential parameters and failure modes of BCCs. In another study of Markazi et al. [12], numerical modeling was performed for semi-rigid boltless connections and experimental results were validated.

The connection influence on overall rack performance under monotonic and cyclic loading was also investigated by Bernuzzi and Castiglioni [13]. The distortion of tabs and the nodal zone were the governing failure modes. Furthermore, the loading types and the design of connectors also affected the behavior of connections. 
Filiatrault et al. [14], Filiatrault et al. [15] and Sideris et al. [16] also investigated the behavior of connection while testing the overall rack structure under seismic loading. Zhao et al. [17] tested the storage rack connections using the standard cantilever testing and useful information was provided. Recently, Castiglioni [18] provided significant information about the seismic performance of SPR systems and highlighted the important design considerations required for seismic design of various components of racking systems included BCCs. Shah et al. [19] highlighted the behavior and performance of SPR BCCs under fire using experimental and numerical investigations. Literature suggests that in order to develop a general analytical model, experimental testing of different types of BEC should be performed [20,21].

This study emphasizes on experimental testing and finite element (FE) analysis of SPR BCCs. Three different thicknesses of the BECs with different number of tabs were tested. The dimensions of the column and pallet beam were kept constant throughout the investigations. The dominant types of failure were observed and the moment-rotation $(\mathrm{M}-\theta)$ relationship was developed. The effect of the thickness and depth of the BEC is also highlighted. A non-linear three dimensional (3D) FE model was generated and validated against the experimental results.

\section{EXPERIMENTAL INVESTIGATIONS}

\subsection{Material Properties}

CFS sections were used for columns and beams. Hot rolled steel was used to manufacture the BEC. Table 1 shows the material properties of the connection components.

Table 1. Material Properties of the Specimens

\begin{tabular}{|c|c|c|c|c|}
\hline Member & $\begin{array}{c}\text { Young's } \\
\text { Modulus (E) } \\
(\mathrm{GPa})\end{array}$ & $\begin{array}{c}\text { Poisson's } \\
\text { ratio }(v)\end{array}$ & $\begin{array}{c}\text { Yield strength } \\
\left(\mathrm{f}_{\mathrm{y}}\right) \\
(\mathrm{MPa})\end{array}$ & $\begin{array}{c}\text { Ultimate } \\
\text { strength }\left(\mathrm{f}_{\mathrm{u}}\right) \\
(\mathrm{MPa})\end{array}$ \\
\cline { 1 - 3 } Column & \multirow{2}{*}{210} & \multirow{2}{*}{0.3} & 459 & 575 \\
\cline { 1 - 1 } Beam & & 353 & 497 \\
\cline { 1 - 1 } BEC & & & 263 & 365 \\
\hline
\end{tabular}

\subsection{Specimen Details}

Six tests were conducted based on the differences in the thickness and number of tabs of the BEC. The type of column perforation is shown in Figure 2.
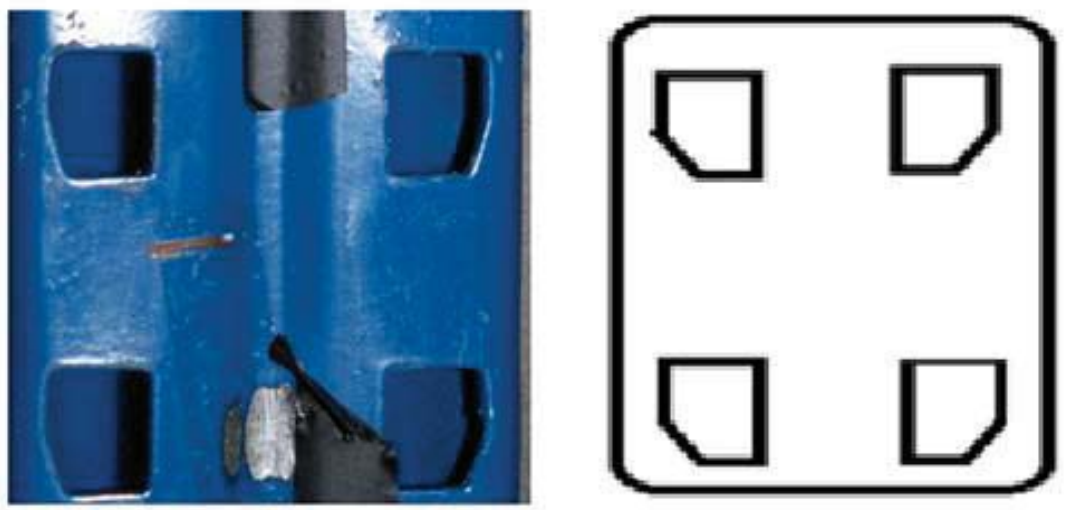
Figure 2. Type of Column Perforation

The cross section and dimensions of the column section are given in Figure 3 (a) and Table 2, respectively. Box beam was used for testing and its cross section is shown in Figure 3 (b). The detail of the beam section is given in Table 3. B represents the types of beam, i.e., box beam. The dimensions and cross section of the BEC are presented in Table 4 and Figure 3 (c), respectively. The numbers are used to show the thickness of the BEC. Symbol 'A' is used to show the connectors with three tabs, whereas symbol ' $\mathrm{B}$ ' is used to show the connector with five tabs. For instance, the type of the BEC ' $2 \mathrm{~A}$ ' shows that the three-tab BEC with a thickness of $2 \mathrm{~mm}$.
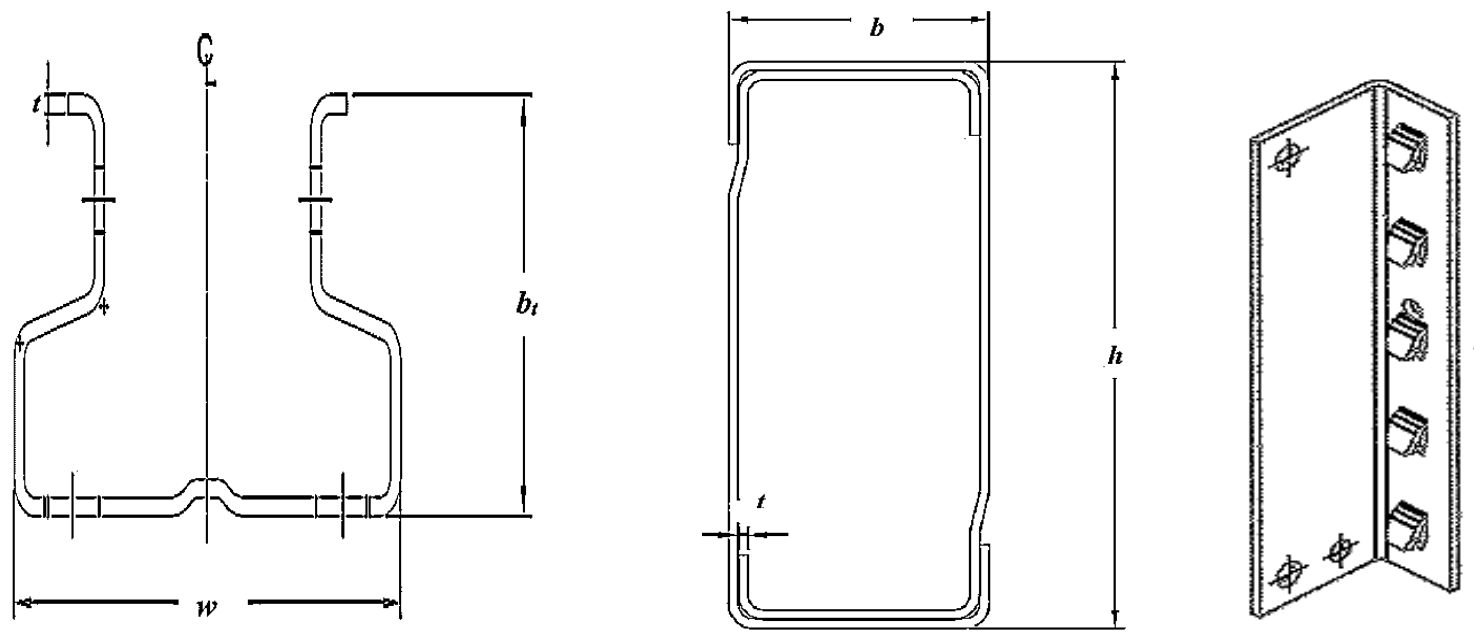

Figure 3. Cross-section of the Connection Components

(a) Column, (b) Beam, (c) BEC

Table 2. Dimension Details of Column

\begin{tabular}{|c|c|c|c|}
\hline $\begin{array}{c}\text { Thickness 't' } \\
(\mathrm{mm})\end{array}$ & $\begin{array}{c}\text { Web 'w' } \\
(\mathrm{mm})\end{array}$ & $\begin{array}{c}\text { Flange width 'bt' } \\
(\mathrm{mm})\end{array}$ & $\begin{array}{c}\text { Height ' } \mathrm{h} \text { ' } \\
(\mathrm{mm})\end{array}$ \\
\hline 2.0 & 112.2 & 67.6 & 500 \\
\hline
\end{tabular}

Table 3. Beam Dimensions

\begin{tabular}{|c|c|c|c|}
\hline Beam type & $\begin{array}{c}\text { Width 'b' } \\
(\mathrm{mm})\end{array}$ & $\begin{array}{c}\text { Depth ' } \mathrm{h} \text { ' } \\
(\mathrm{mm})\end{array}$ & $\begin{array}{c}\text { Thickness ' } \mathrm{t} \text { ' } \\
(\mathrm{mm})\end{array}$ \\
\hline B & 40 & 92 & 1.5 \\
\hline
\end{tabular}

Table 4. Dimension Detail of the Tested BECs

\begin{tabular}{|c|c|c|c|c|c|}
\hline $\begin{array}{c}\text { Type of the } \\
\text { BEC }\end{array}$ & $\begin{array}{c}\text { Number of } \\
\text { tabs }\end{array}$ & $\begin{array}{c}\text { Breadth 'b' } \\
(\mathrm{mm})\end{array}$ & $\begin{array}{c}\text { Width 'w' } \\
(\mathrm{mm})\end{array}$ & $\begin{array}{c}\text { Depth 'h' } \\
(\mathrm{mm})\end{array}$ & $\begin{array}{c}\text { Thicknes } \\
\mathrm{s} \text { 't' } \\
(\mathrm{mm})\end{array}$ \\
\hline 2A & 3 & 40 & 64 & 150 & 2 \\
\hline 2B & 5 & 40 & 64 & 250 & 2 \\
\hline 4A & 3 & 40 & 64 & 150 & 4 \\
\hline 4B & 5 & 40 & 64 & 250 & 4 \\
\hline 6A & 3 & 40 & 64 & 150 & 6 \\
\hline 6B & 5 & 40 & 64 & 250 & 6 \\
\hline
\end{tabular}


Each set of specimen is given a specific specimen ID. For example, in the specimen ID 'B-2.0UT-92BD-3T-2CT', 'B' indicates the type of beam (box beam), 2.0UT represents the column thickness as $2.0 \mathrm{~mm}, 92 \mathrm{BD}$ represents the depth of beam as $92 \mathrm{~mm}, 3 \mathrm{~T}$ represents the number of tabs in the connector which is three, and 2CT represents the thickness of the BEC, which is $2 \mathrm{~mm}$. For an easy understanding, each specimen has been assigned a numeric ID which is listed in Table 5 .

Table 5. Numeric ID Assigned to the Specimens

\begin{tabular}{|c|c|}
\hline Specimen ID & Numeric ID \\
\hline B-2.0UT-92BD-3T-2CT & Specimen 1 \\
\hline B-2.0UT-92BD-3T-4CT & Specimen 2 \\
\hline B-2.0UT-92BD-3T-6CT & Specimen 3 \\
\hline B-2.0UT-92BD-5T-2CT & Specimen 4 \\
\hline B-2.0UT-92BD-5T-4CT & Specimen 5 \\
\hline B-2.0UT-92BD-5T-6CT & Specimen 6 \\
\hline
\end{tabular}

A sketch of tested specimen 5 with its dimensions is shown in Figure 4. The connection depicts a BEC of $4 \mathrm{~mm}$ is welded to one end of the beam with tabs punched into it. The leg of the angle with tabs is in contact with column web after assembly, while there is a $2 \mathrm{~mm}$ gap between the second legs, perpendicular to the column web. Figure 4 is modified from Figure 2 of [2]. However, in this study, the tabs of the BEC were reversely engaged into the column perforations.

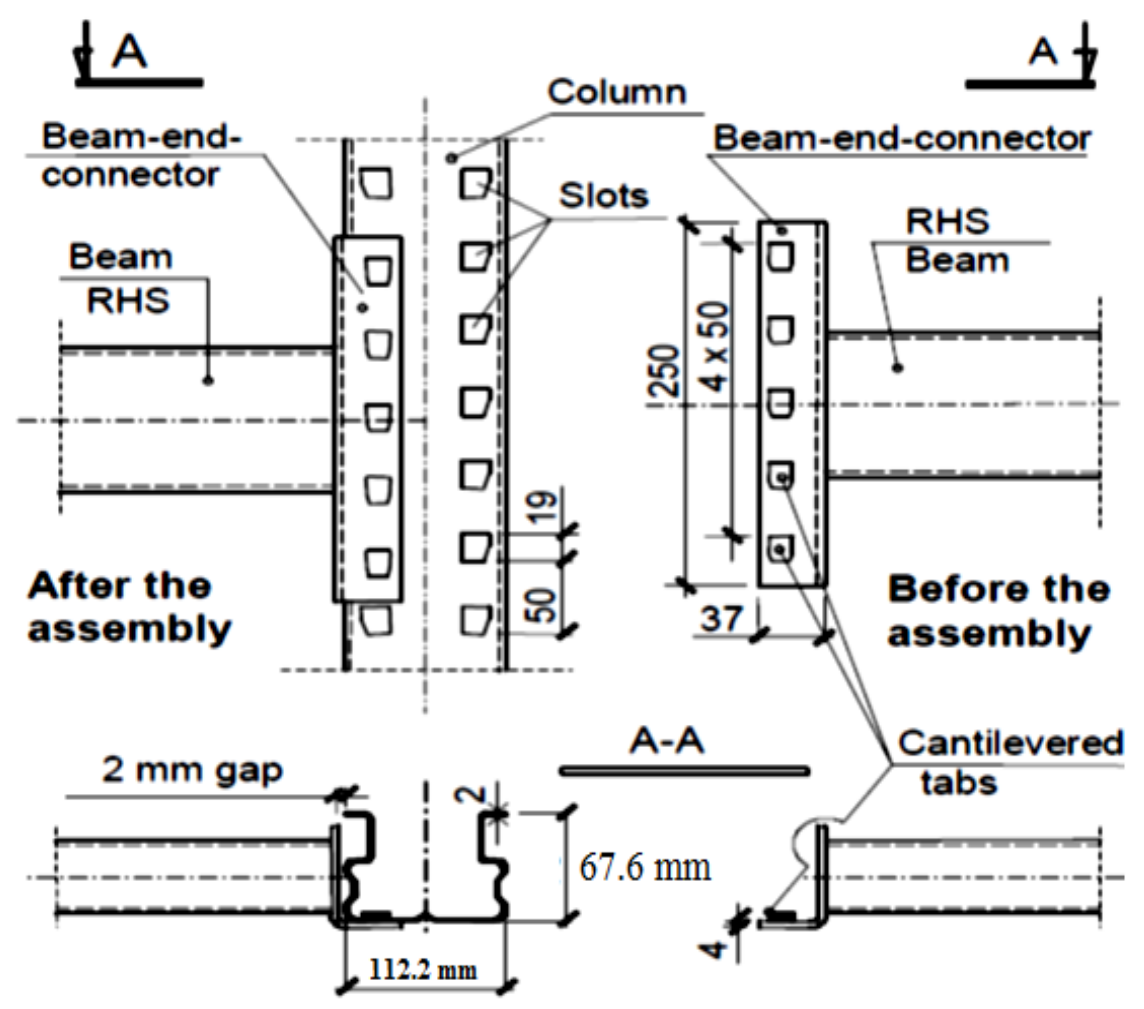

Figure 4. Dimensions of Tested Connection (Specimen 5)

\subsection{Selection of Test Method}

The international design standards of storage rack design such as The Rack Manufacturing Institute (RMI) [22], European Committee for Standardization (EN 15512) [23] and Standards Australia (AS4084) [24] suggest alternative testing methods for the testing of SPR BCCs. The RMI [22] and AS4084 [24] suggest 'Cantilever test method' and 'Portal frame test method', whereas the EN 
15512 [23] suggest only Cantilever Test Method which considers a cantilever beam connected to the perforations of column through tabs. This test method was modified by researchers $[25,26]$ by attaching an extra beam to the other side of column and placing the column in between two full length beams and, hence, is called the double cantilever test method. The efficiency of the double-cantilever test method for the testing of SPR BCCs is clearly evident in various studies [25-27]. This study has followed the double-cantilever test method to forecast the M- $\theta$ behavior of SPR BCCs.

\section{$2.4 \quad$ Testing Arrangement}

Figure 5 shows the schematic diagram of experimental arrangement used in this research for connection testing. The column was aligned accurately under the loading instrument and two pallet beams were then attached to the perforations of column with reversely positioned tabs on both left and right sides. In order to prevent the lateral twisting of pallet beams near the connection, the beams were adjusted into two rectangular hollow sections which were welded to angle sections and bolted to strong floor. Roller supports with a distance of $2 \mathrm{~m}$ between each other were provided for the unconnected ends of both the beams. A displacement controlled loading method was chosen and the force was applied at the top of the column through a $50 \mathrm{kN}$ hydraulic actuator at a rate of 1 $\mathrm{mm} / \mathrm{min}$ until the a drop of $1 \mathrm{kN}$ in the load was observed or the connection showed no resistance to further load. Applying the load at the top of the column caused the top of the connection in compression and the bottom in tension. EN 15512 [23] suggests that the end rotation of beams can be evaluated through the inclinometers placed closer to the connection. Two digital inclinometers were placed as possible as close to the connection and the end the end rotation of beams was directly recorded. The deflection in beams was monitored by two dial gauges, placed at L/4 distance from the center of roller support. A dial gauge was attached to the column at its bottom, in order to record central deflection. The dial gauges were connected to a computerized data logger to record real time loading and displacements.

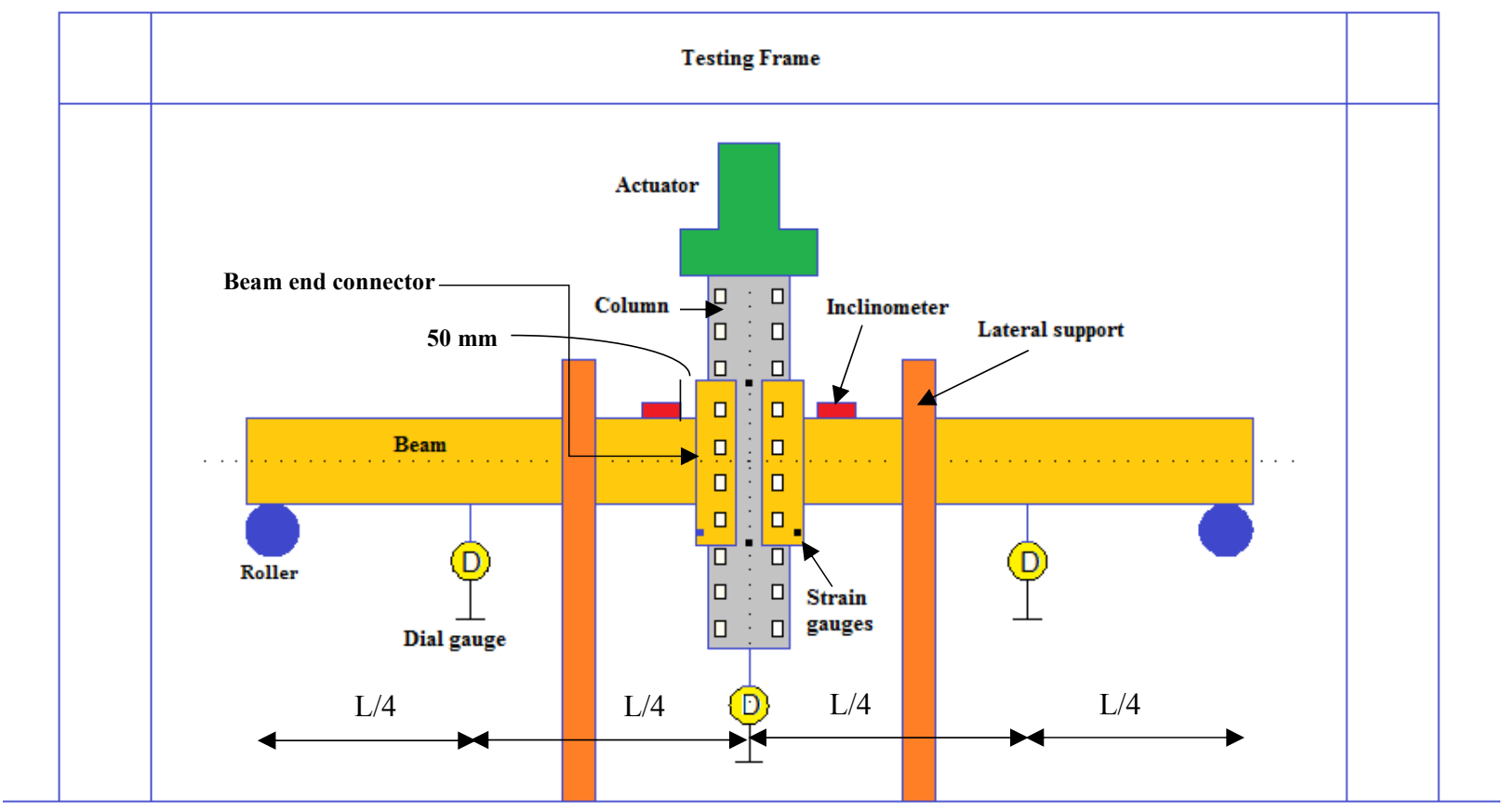

Figure 5. Schematic Diagram of Test Set-up 


\section{RESULTS AND DISCUSSION}

\subsection{M- $\quad$ Behavior and stiffness}

All the specimens showed non-linear behavior from the start. This may be either due to the imperfections in the constructional design of the specimens or non-linear geometrical configurations [28]. Figure 6 shows the M- $\theta$ graphs for all six connections. It can be seen from Figure 6 that the decline in the moment capacity was occurred in the ultimate stage. It may be due to the complete rupture of top two tabs after sustaining a reasonable amount of load in its yield stage. The stiffness was calculated using Equal area method, however no correction factor was applied to the achieved moments; mainly due to the larger stiffness of the beam sections. Table 6 presents the test results for all six specimens.

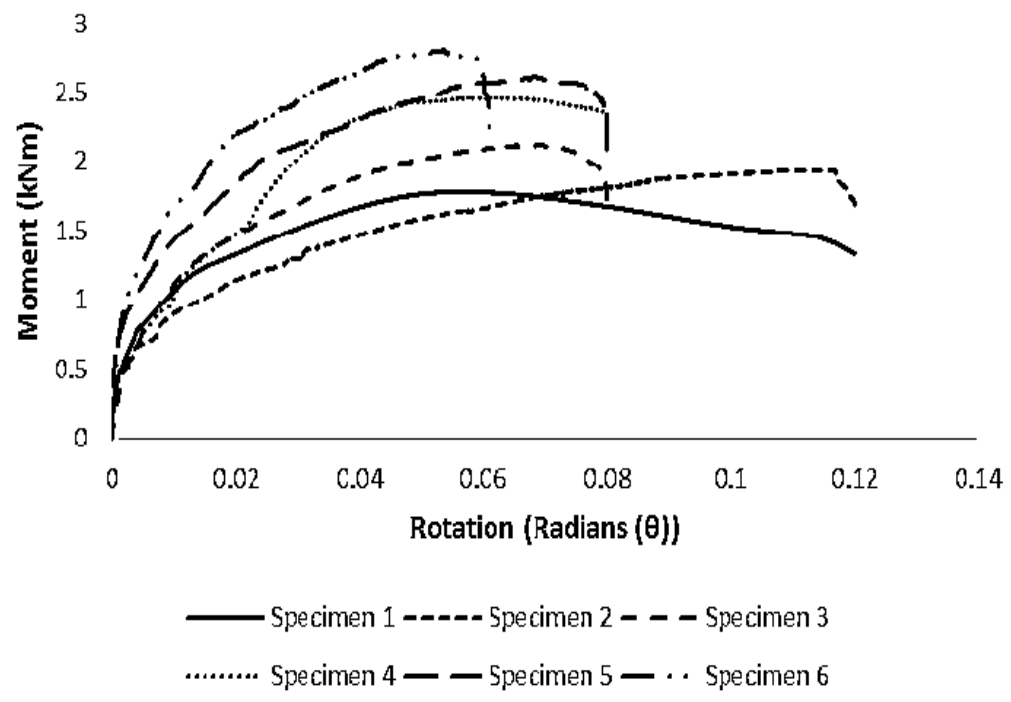

Figure 6. M- $\theta$ Curves for All Tested Specimens

Table 6. Test Results

\begin{tabular}{|c|c|c|c|c|}
\hline Specimen & $\begin{array}{c}\text { Failure Load } \\
(\mathrm{kN})\end{array}$ & $\begin{array}{c}\text { Ultimate Moment } \\
\text { Capacity } \\
(\mathrm{kNm})\end{array}$ & $\begin{array}{c}\text { Rotation } \\
(\text { Radians })\end{array}$ & $\begin{array}{c}\text { Stiffness } \\
(\mathrm{kNm} / \mathrm{rad})\end{array}$ \\
\hline 1 & 3.79 & 1.78 & 0.12 & 23.36 \\
\hline 2 & 4.06 & 1.91 & 0.12 & 26.54 \\
\hline 3 & 4.52 & 2.13 & 0.08 & 31.1 \\
\hline 4 & 5.23 & 2.46 & 0.08 & 36.6 \\
\hline 5 & 5.54 & 2.61 & 0.08 & 46.8 \\
\hline 6 & 5.97 & 2.81 & 0.06 & 49.23 \\
\hline
\end{tabular}

\subsection{Failure Modes}

The failure was considered when a drop of $1 \mathrm{kN}$ was observed in the applied load. During the experimental testing, three types of failures were observed. These types included: (i) failure of connector tabs (ii) deformation of column, and (iii) distortion of the BEC itself. For specimen 1, with the increase in load, the top two tabs tried to come out from the column perforations, cut the column web and ruptured completely. The last tab did not cause any cut in the web and just came out from the column slot. The failure of specimen ' 2 ' was similar to the specimen ' 1 ', except the difference in the value of failure load. A considerable distortion of the BEC was also noticed. In the case of specimen ' 3 ', the greater number of tabs and increased thickness of the BEC allowed the specimen to sustain larger in-plane moment. No tab showed a complete rupture, however, the 
failure initiated with the distortion of top tabs and ended with the distortion of column web caused by the cuts developed by the tabs. For specimens ' $4-6$ ', the amount of failure load was extensively higher than specimens, ' $1-3$ ' and the full rupture of any tab was not noticed. However, tearing of column was observed near the top tabs under compression. Overall, a ductile behavior was shown by almost all the specimens. The typical failure modes of the BEC, the connection and the column and are shown in Figure 7 (a-c), respectively.

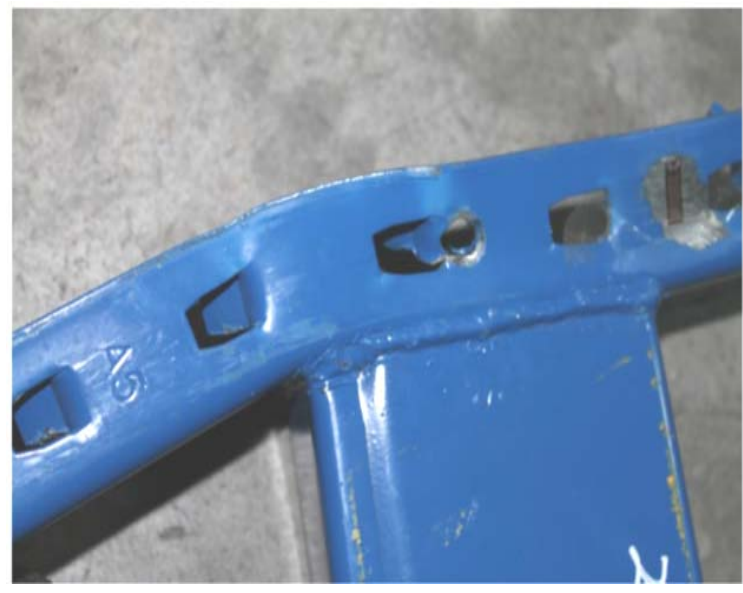

(a)

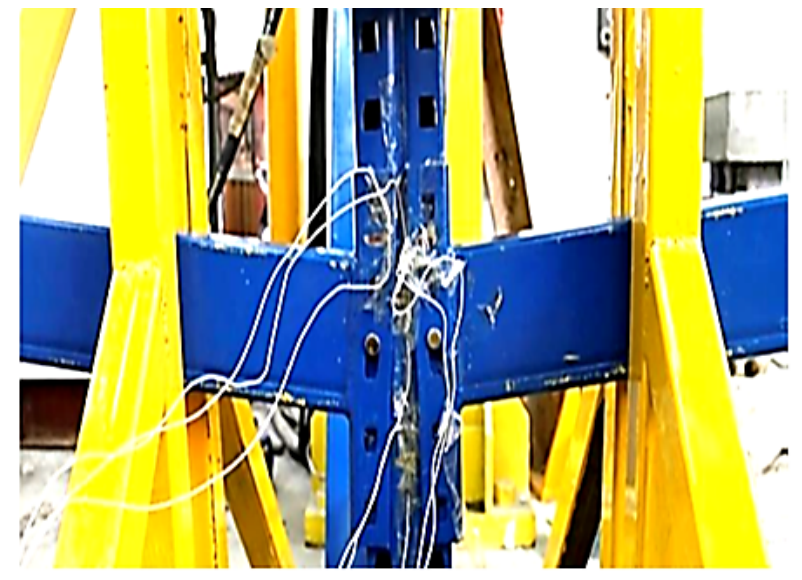

(b)

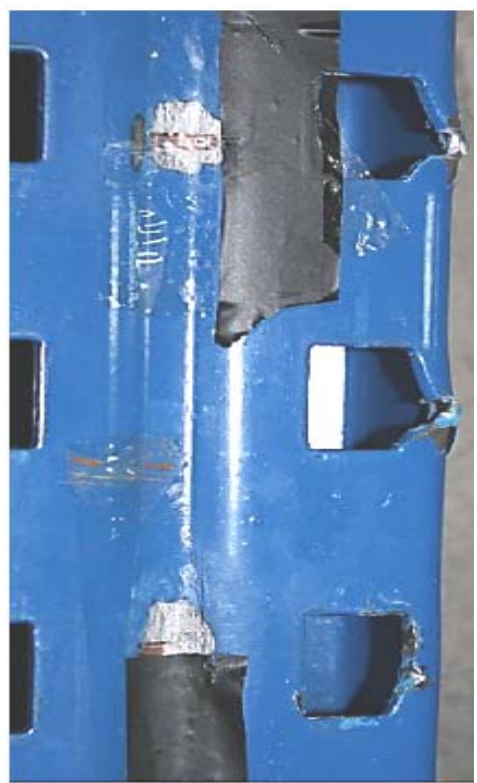

(c)

Figure 7. Failure Modes

(a) BEC, (b) connection, (c) column

\section{EFFECT OF GEOMETRY OF THE BEC ON THE CONNECTION PERFORMANCE}

The parameters analyzed in this study are the thickness of the BEC and number of tabs in the BEC. Figure 6 and Table 6 show that specimen 2 showed 7\% higher moment capacity than specimen 1 . The stiffness was increased by $12 \%$. The similar behavior was observed when the thickness of BEC was changed from $2 \mathrm{~mm}$ to $6 \mathrm{~mm}$. Specimen 3 showed $16 \%$ increased moment capacity as 
compared to the specimen 1 . A $24 \%$ increase in the stiffness was observed. These statistics clearly shows the effect of increased thickness of the BEC. When the number of tabs changed from 3 to 5 (from specimen 1 to specimen 4), the moment capacity and stiffness of specimen 4 were increased by $28 \%$ and $37 \%$, respectively. This shows that in all the cases, the geometrical properties has affected the stiffness of the connection.

\section{FINITE ELEMENT (FE) MODELING}

\subsection{Modeling Approach}

A non-linear 3D FE model was developed on a commercially available software ABAQUS [29]. The FE model was capable of incorporating the geometrical and material non-linearity. The specimen 2 was considered for FE modeling and a bi-linear elasto-plastic model was developed based on the material properties defined in Table 1. The column, pallet beam and the BEC were modeled using Element C3D8R (i.e., continuum 3D with eight nodes and reduced integration). The number of elements in each beam/ BEC were 18812 whereas in column, the number of element was 46404. Distortion energy density criterion or von Mises yield criterion is used to predict yielding. It should be noted that the few of previous studies did not consider the modeling of tabs that hampers to obtain realistic modeling of the strength and deformation behavior of connector tabs which were the most crucial element of SPR BCCs. In this study, SOLID element was used to model the tabs. Although, modeling of tabs as solid element complexed the model, nevertheless, the original experimental conditions were replicated and helped in evaluating the actual deformation behavior of tabs. Figure 8 shows the geometry of modeled tabs.

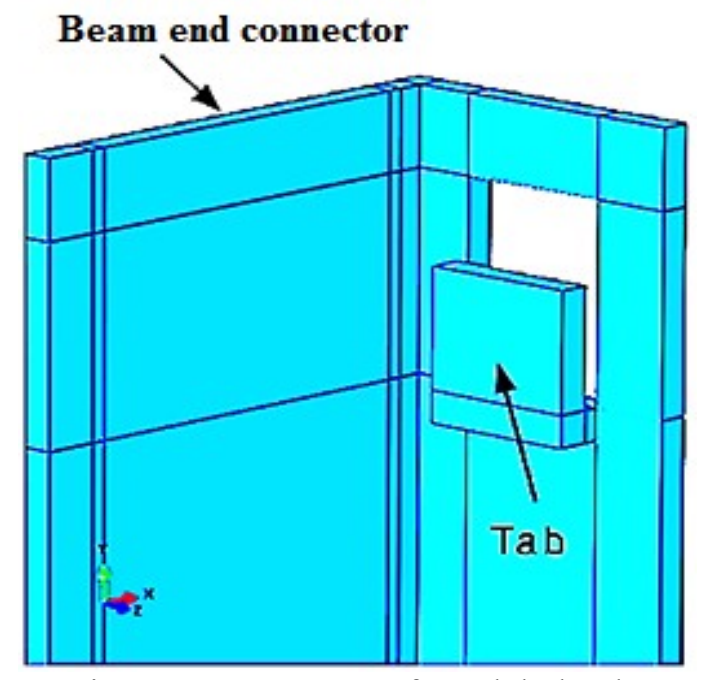

Figure 8. Geometry of Modeled Tabs

\subsection{Surface Interaction}

The surface-to-surface interactions (front and side) between the column and the BEC and the column and the tabs were assigned through tangential frictionless contact, and normal hard contact and tangential frictionless contact, respectively. The tangential frictionless contact removes the relative movement between the surfaces of the column and the tab, whereas the normal hard contact restrains the sideways movement (normal to longitudinal axes) of the column. 


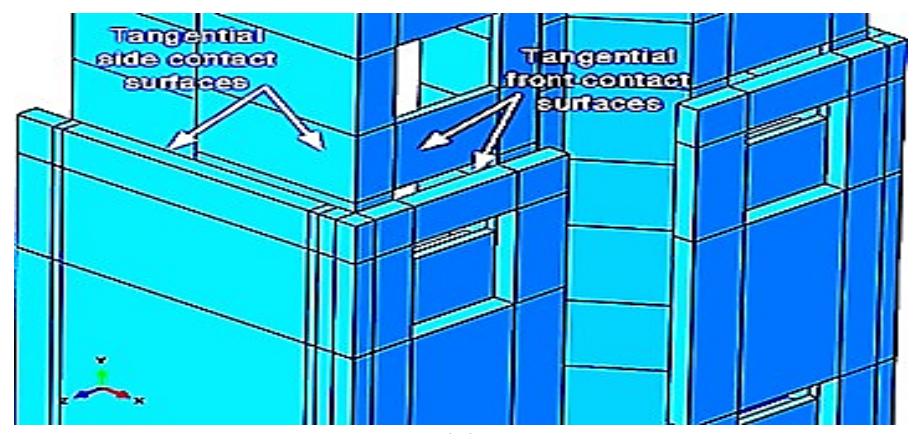

(a)

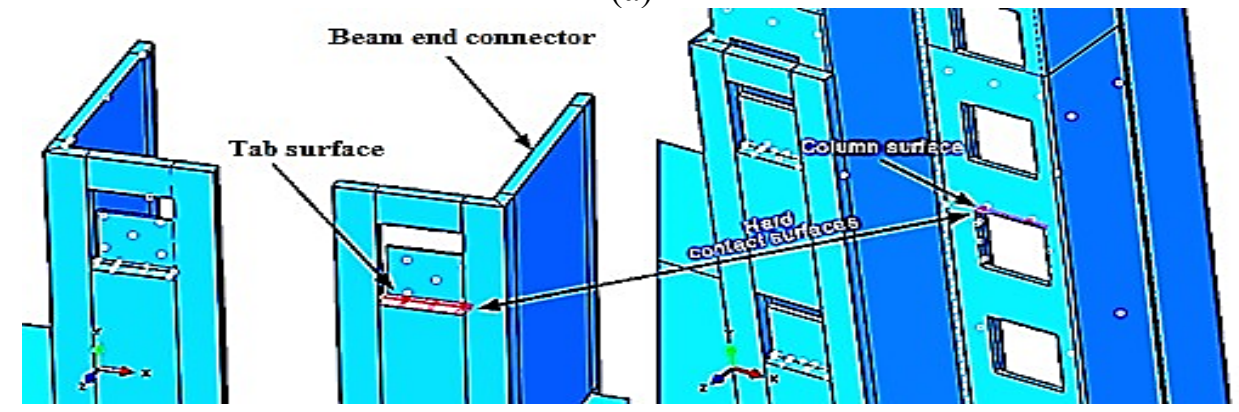

(b)

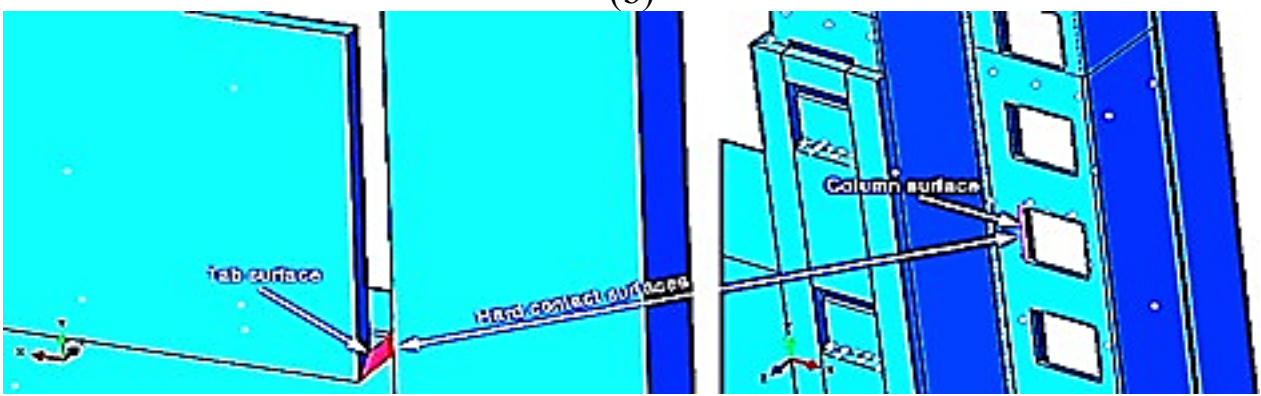

(c)
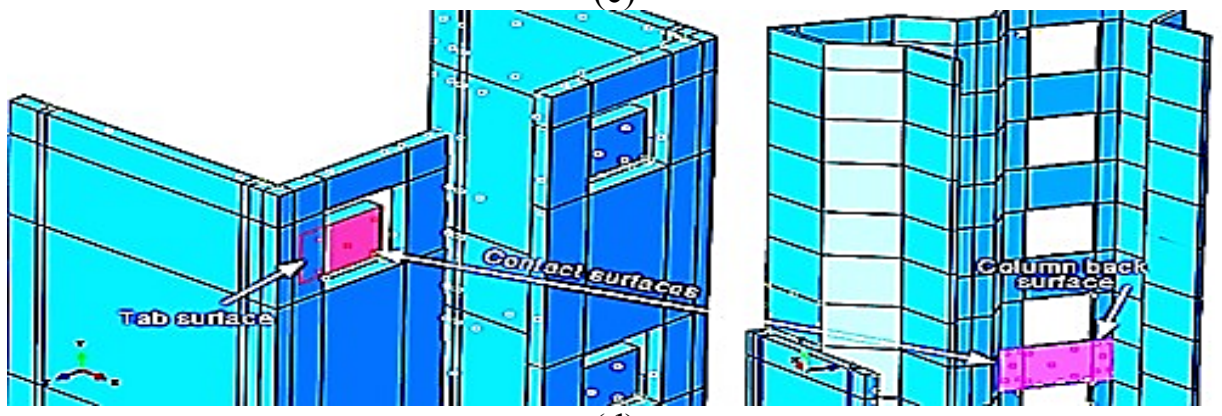

(d)

Figure 9. Surface to Surface Interaction Among Components

\subsection{Loading and Boundary Conditions}

Simulating the boundary conditions adopted in the experimental investigations, the following boundary conditions were modeled: $\mathrm{Ux}=\mathrm{Uy}=\mathrm{URy}=\mathrm{URz}=0$, where $\mathrm{U}$ and $\mathrm{UR}$ are the displacement and rotation, respectively. The boundary conditions assigned to the column were $\mathrm{Ux}=$ $\mathrm{Uz}=\mathrm{URx}=\mathrm{URy}=\mathrm{URz}=0$, where $\mathrm{Uy}$ is the applied displacement. The displacement loading was applied on the top of the column in 10,000 steps. The step size was further sub-divided, resulting in a displacement rate of $70 \times 10^{-4} \mathrm{~mm} / \mathrm{sub}$-step size. This minor value avoids the influence of strain rate on the structural behavior of the assembly. 


\section{$5.4 \quad$ Meshing}

A structured discretization scheme was employed to mesh the beams and BECs, and a structured free meshing scheme was adopted for the column because of its complex geometry. Experimental observations showed large deformations at the punching point of tabs with the BEC; hence, this region was assigned with a high-density mesh. Various types of non-linearity such as contact, geometric and material increased the convergence issues at some regions during simulation, however, this problem was successfully overcome by decreasing the time step size and enhancing the mesh density in those regions. Figure 10 shows the complete geometry of the modeled connection.

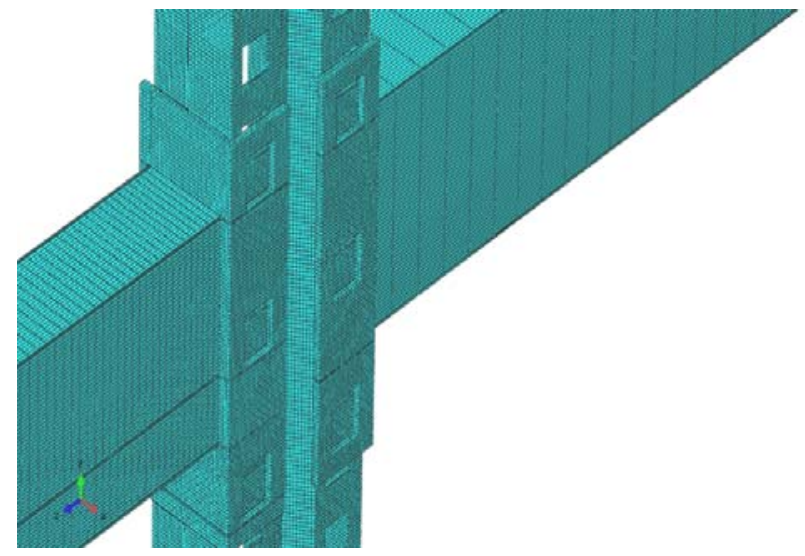

Figure 10. Complete Geometry of the Modeled Connection

\subsection{FE Results}

\subsubsection{Failure modes}

The failure modes showed by FE simulation were very much closer to the experimental failure modes. Again, the failure of tabs was the major failure mode showed by FE analysis. Similar to the experimental investigations, the bottom tabs of the connector showed high deformations and tried to cut the column perforations. The disengagement of tabs and distortion of column material were observed by FE model at a relatively lesser intensity as compared to the experimental results which, consequently, led to a higher ultimate moment capacity. The BEC showed noteworthy twist in the tension region. The FE failure of the BEC is illustrated in Figure 11. A closer look of the failure of bottom tab is presented in Figure 12. The deformation of the column is presented in Figure 13. It can be seen that the top and bottom tabs distorted the column slots. The failure of full connection is presented in Figure 14.

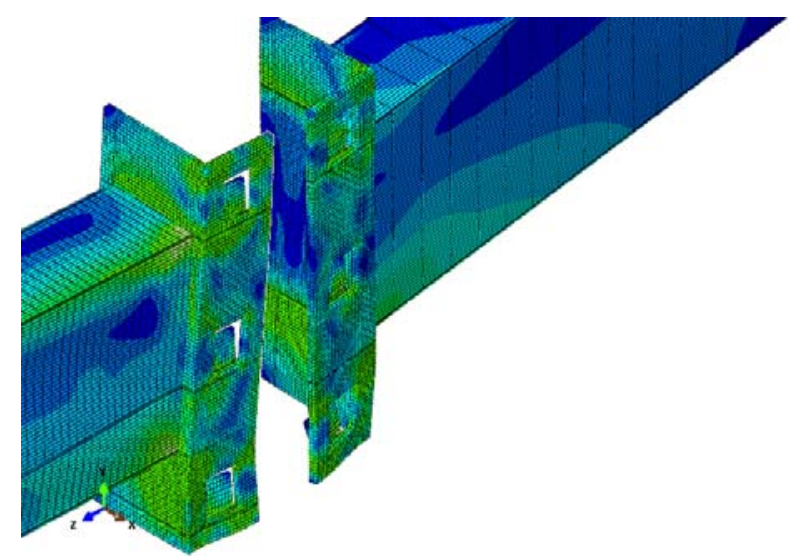

Figure 11. Failure of the Tabs and the Beam End Connector 

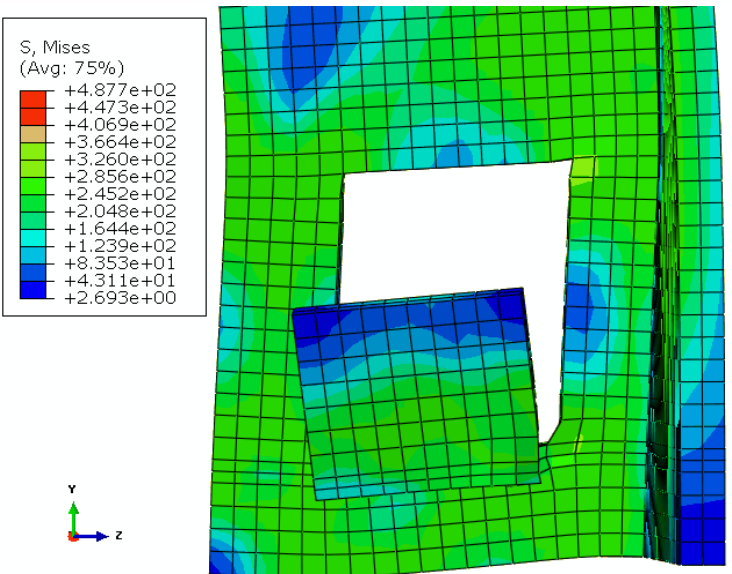

Figure 12. Failure of the Bottom Tab

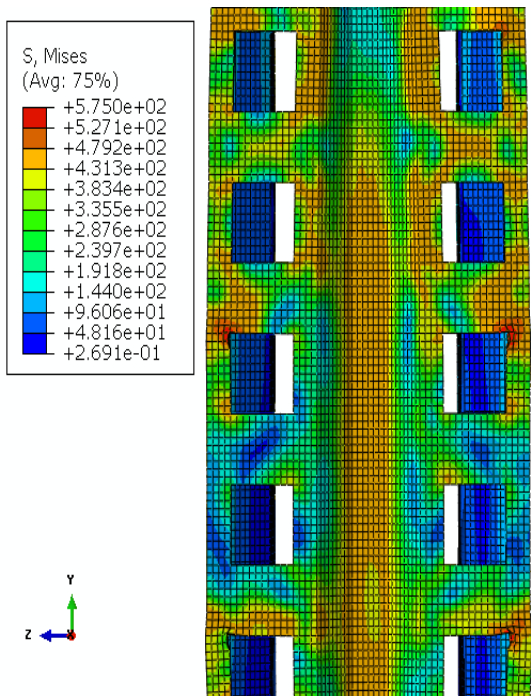

Figure 13. Failure of Column

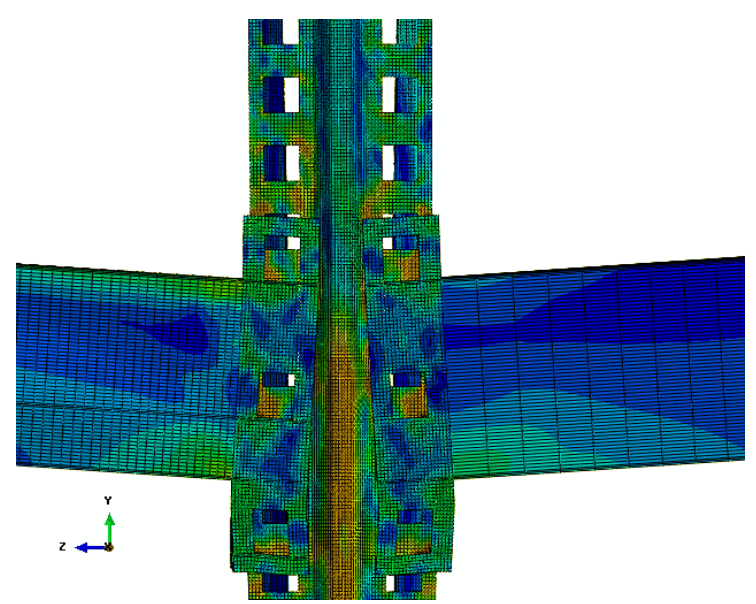

Figure 14. Failure of the Connection 


\subsubsection{Stress pattern}

It can be observed from Figure 13 that the highest stress value in the column occurred in the tension region of BCC. Therefore, the tabs in third slot of the column experienced higher stress compared with those in the compression zone because of the chosen point of application of the load onto the column. This phenomenon substantiates the case of selecting the double cantilever test method for testing purpose. Furthermore, engaging the tabs reversely into the column slots generated higher stress concentration at the joining region of the tabs and the column.

The Von Mises stress distribution at a specific point in the last tab in the tension zone is shown in Figure 15(a), while Figure 15(b) shows the variation of equivalent stress (Von Mises stress) at point 1 as shown in Figure 15(a) with respect to column vertical displacement. Point 1 is the upper joining point between tab and column. It is evident from Figure 15(b) that the equivalent stress reaches to $300 \mathrm{MPa}$ which is the approximate yield strength $(304 \mathrm{MPa})$ of beam end connector, as given in Table 1. This shows the permanent failure of tab due to excessive deformation. Furthermore, stress relaxation at the initial stage of deformation is observed. This could be happened due to slipping action between column surface and tab but at intermediate and higher stages of deformation, stress increment is observed due to significant deformation of tab. Stress magnitude is higher than yield strength, indicating that permanent deformation has occurred in the tabs.

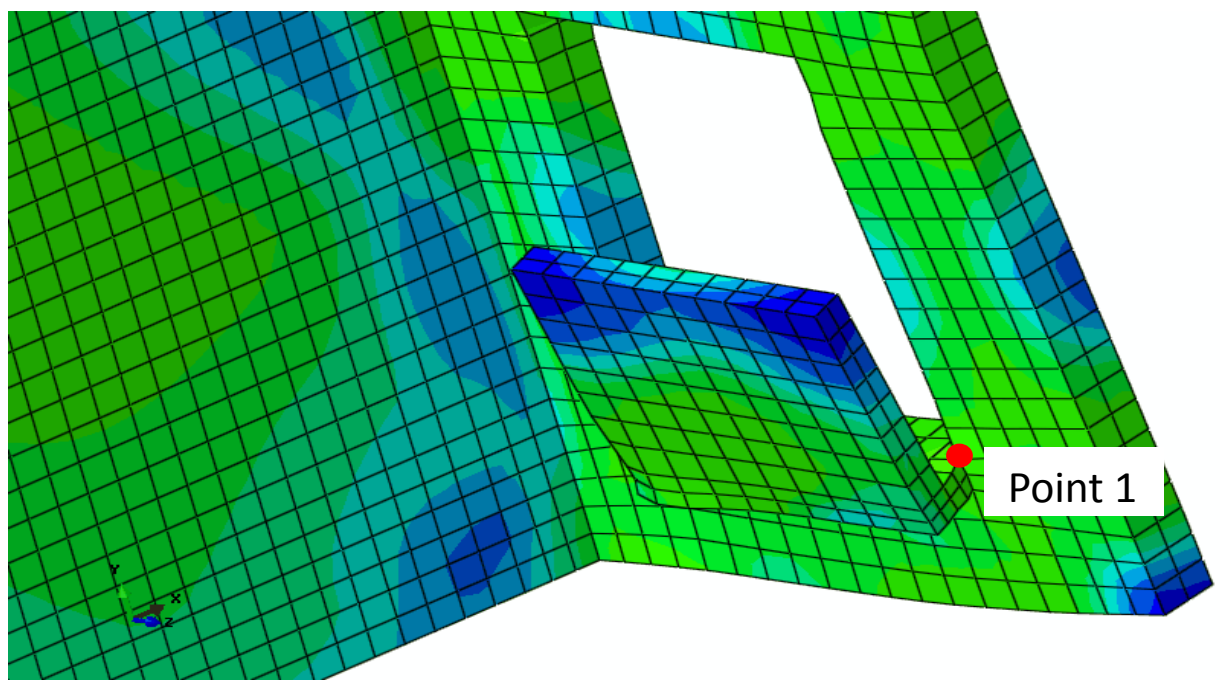

(a) Stress distribution at a specific point in the last tab

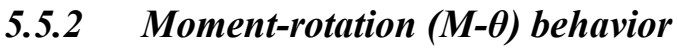

A higher level of similarity was noticed between the FE and experimental M- $\theta$ behavior of the BCCs. The FE model was able to predict the experimental behavior to a large extent. The initial stiffness portion of the curve matches that of the test results well. However, a minor variation was observed between the failures of column perforations exhibited by the experimental and FE investigations. In the test, failure occurred with the tearing of column perforation by the lower tabs. The tabs slit the column wall. Meanwhile, the FE model was unable to consider the same intensity of distortion of column slots. Therefore, the connection's ultimate moment capacity obtained by using the FE model was higher than that obtained from the test. A comparison of the $\mathrm{M}-\theta$ graphs plotted for specimens 2 for both experimental and FE investigations is provided in Figure 16. Table 7 shows a comparison of the moment capacity and stiffness of the experimental and FE investigations. 


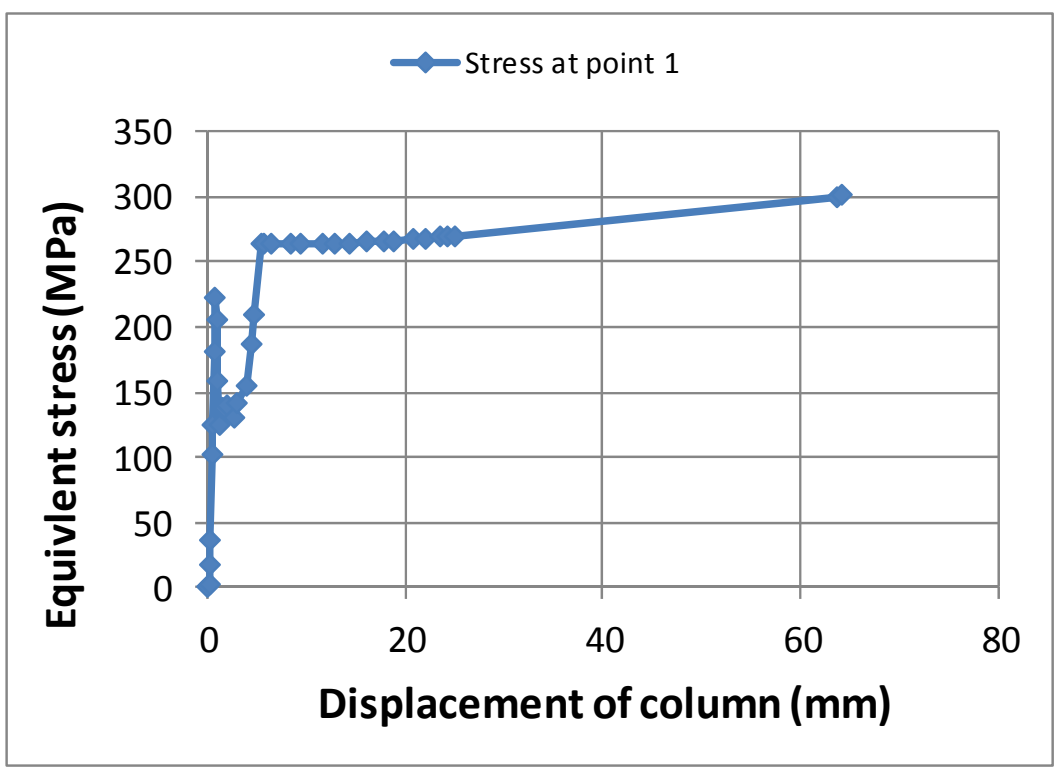

(a) Equivalent stress and column displacement graph

Figure 15. Von Mises Stress Distribution in the Tab in the Tension Zone

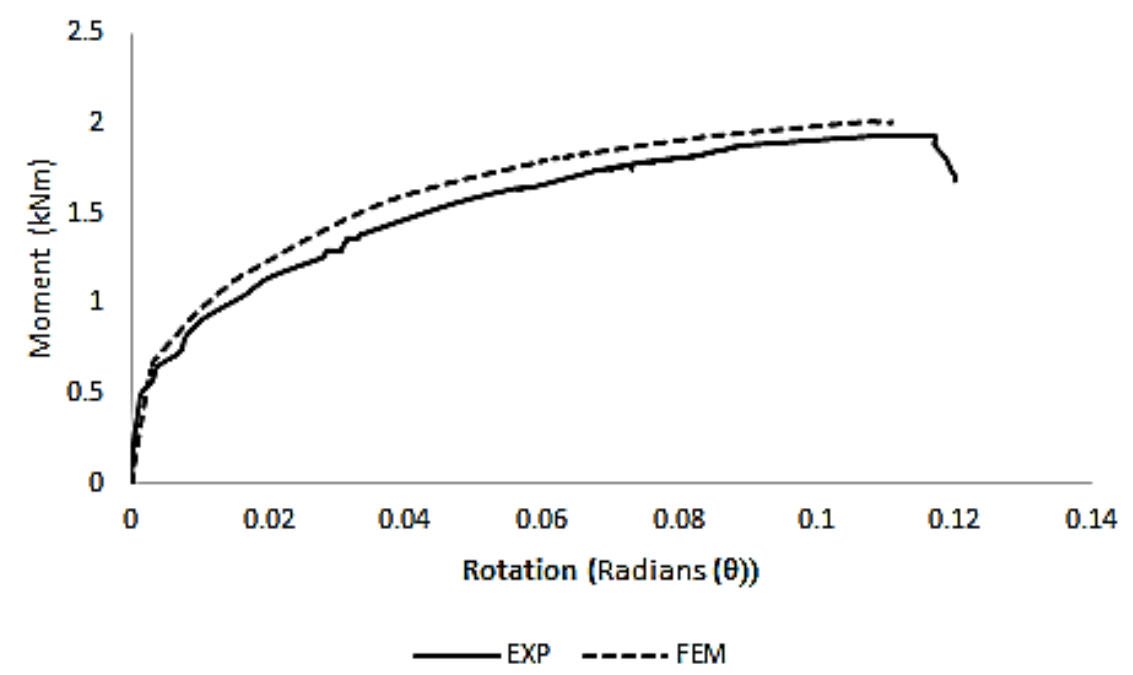

Figure 16. Experimental and FEM Comparison of the M- $\theta$ Graphs for Specimens 2

Table 7. Comparison of the Moment Capacity and Stiffness of the Experimental and FE Investigations for Specimen 2

\begin{tabular}{|c|c|c|c|c|}
\hline Specimen & \multicolumn{2}{|c|}{$\begin{array}{c}\text { Ultimate Moment capacity } \\
(\mathrm{kNm})\end{array}$} & \multicolumn{2}{|c|}{ Stiffness (kNm/rad) } \\
\hline \multirow{2}{*}{2} & Experimental & FEM & Experimental & FEM \\
\cline { 2 - 5 } & 1.91 & 2.01 & 26.54 & 27.42 \\
\hline
\end{tabular}




\section{CONCLUSION}

The variation in the geometrical features of the commercially available BECs used in the SPR BCCs is the major hurdle in the development of a generalized analytical approach to predict the M- $\theta$ relationship for SPR BCCs. The main contribution of this study is twofold: (1) to identify the effect of the geometry of the BEC on the strength and stiffness of SPR BCCs (ii) to identify the possible failure modes of steel rack connections. A series of experiments was performed by varying the thickness of the BEC and number of tabs in the BEC. FE simulations were performed and their results were validated against experimental findings. The FE model showed a good agreement with experimental results. It was revealed by the experimental findings that the failure of all the specimens was originated due to the distortion of tabs which promoted the unbalanced stress concentration in the column perforation and consequently, into the beams. The tearing of column material and the twist in the $\mathrm{BEC}$ for the specimens with relatively lesser thickness and lesser number of tabs in the BEC was observed. The influence of parameters was also investigated. A comparison of the achieved $\mathrm{M}-\theta$ relationship showed that the number of tabs is more critical factor than the connector thickness for the overall performance of SPR BCCs.

\section{ACKNOWLEDGEMENT}

The study presented herein was made possible by the University of Malaya Grants: (i) UMRG RP004C-13AET and, (ii) PPP grant PG055-2013B. The authors would like to acknowledge the support.

\section{REFERENCES}

[1] Pekoz, T. and Winter, G., "Cold-Formed Steel Rack Structures", Proceedings of Second Specialty Conference on Cold-Formed Steel Structures. USA, 1973.

[2] Slęczka, L. and Kozłowski, A., "Experimental and Theoretical Investigations of Pallet Racks Connections", Advanced Steel Construction, 2007, Vol. 3, No. 2, pp. 607-610.

[3] Sajja, S., Beale, R.G. and Godley, M.H.R., "Shear Stiffness of Pallet Rack Column Frames", Journal of Constructional Steel Research, 2008, Vol. 64, pp. 867-874.

[4] Moen, C.D. and Schafer, B., "Elastic Buckling of Cold-formed Steel Columns and Beams with Holes", Engineering Structures, 2009, Vol. 31, pp. 2812-2824.

[5] Kozłowski, A. and Ślęczka, L., "Preliminary Component Method Model of Storage Rack Joint”, Proceedings of Connections in Steel Structures V. Amsterdam, 2004, pp. 253-262.

[6] Gilbert, B.P. and Rasmussen, K.J.R., "Experimental Test on Steel Storage Rack Components", Research Report No R899, University of Sydney, Australia, 2009.

[7] Al-Jabri, K.S., Burgess, I.W., Lennon, T. and Plank, R.J., "Moment-rotation-temperature Curves for Semi-rigid Joints", Journal of Constructional Steel Research, 2005, Vol. 61, No. 3, pp. 281-303.

[8] Al-Jabri, K.S. and Al-Alawi, S.M., "Predicting the Behaviour of Semi-rigid Joints in Fire Using an Artificial Neural Network", Steel Structures, 2007, Vol. 7, pp. 209-217.

[9] Lee, Y.H., Tan, C.S., Mohammad, S., Md Tahir, M. and Shek, P.N., "Review on Cold-formed Steel Connections", The Scientific World Journal, 2014.

[10] Ali, B. A., Saad, S., Osman, M. H. and Ahmad, Y., "Finite Element Analysis of Cold-formed Steel Connections", International Journal of Engineering, 2011, Vol. 5, No. 2, pp. 55-61.

[11] Markazi, F.D., Beale, R.G. and Godley, M.H.R., "Experimental Analysis of Semi-rigid Boltless Connectors", Thin- walled structures, 1997, Vol. 28, No. 1, pp. 57-87. 
[12] Markazi, F.D., Beale, R.G. and Godley, M.H.R., "Numerical Modelling of Semi-rigid Boltless Connectors", Computers \& Structures, 2001, Vol. 79, pp. 2391-2402.

[13] Bernuzzi, C. and Castiglioni, C.A., "Experimental Analysis on the Cyclic Behaviour of Beam-to-column Joints in Steel Storage Pallet Racks", Thin-Walled Structures, 2001, Vol. 39, pp. 841-859.

[14] Filiatrault, A., Bachman, R.E. and Mahoney, M.G., "Performance-based Seismic Design of Pallet-type Steel Storage Racks", Earthquake spectra, 2006, Vol. 22, pp. 47-64.

[15] Filiatrault, A., Higgins, P.S., Wanitkorkul, A. and Courtwright, J, "Experimental Stiffness of Pallet-Type Steel Storage Rack Teardrop Connectors", Practice Periodical on Structural Design and Construction, 2007, Vol. 12, No. 4, pp. 210-215.

[16] Sideris, P., Filiatrault, A., Leclerc, M. and Tremblay, R., "Experimental Investigation on the Seismic Behavior of Palletized Merchandise in Steel Storage Racks", Earthquake Spectra, 2010, Vol. 26, pp. 209-233.

[17] Zhao, X., Wang, T., Chen, Y. and Sivakumaran, K.S., "Flexural Behavior of Steel Storage Rack Beam-to-column Connections", Journal of Constructional Steel Research, 2014, Vol. 99, pp. 161-175.

[18] Castiglioni, C. A., Seismic Behavior of Steel Storage Pallet Racking Systems, Springer 2016.

[19] Shah, S. N. R., Sulong, N.H. R., Shariati, M., Khan, R. and Jumaat, M.Z., "Behavior of Steel Pallet Rack Beam-to-column Connections at Elevated Temperatures", Thin-Walled Structures, 2016, Vol. 106, pp. 471-483.

[20] Shah, S.N.R., Sulong, N.H.R., Shariati, M. and Jumaat, M.Z., "Steel Rack Connections: Identification of Most Influential Factors and a Comparison of Stiffness Design Methods", PLOS One, 2015, Vol. 10, No. 10, e0139422.

[21] Shah, S.N.R., Sulong, N.H.R.., Khan, R., Shariati, M. and Jumaat, M.Z., "Behavior of Industrial Steel Rack Connections”, Mechanical Systems and Signal Processing, 2016, Vol. 70-71, pp. 716-725.

[22] Rack Manufacturers Institute (RMI), Specification for the Design, Testing and Utilization of Industrial Steel Storage Racks, Material Handling Industry, MH16.1. Charlotte, NC, 2012

[23] EN 15512. Steel Static Storage Systems-Adjustable Pallet Racking Systems-Principles for Structural Design, European Committee for Standardization. Brussels, Belgium, 2009.

[24] AS4084, Standards Australia. Steel Storage Racking, Sydney, Australia, 2012.

[25] Bajoria, K.M. and Talikoti, R.S., "Determination of Flexibility of Beam to Column Connectors used in Thin Walled Cold Formed Steel Pallet Racking Systems", Thin Walled Structures, 2006, Vol. 44, pp. 372-380.

[26] Sangle, K.K.., Bajoria, K.M. and Talicotti, R.S., "Stability and Dynamic Analysis of Cold-formed Storage Rack Structures with Semirigid Connections", International Journal of Structural Stability and Dynamics, 2011, Vol. 11, No. 6, pp. 1059-1088.

[27] Prabha, P., Marimuthu, V., Saravanan, M. and Jayachandran, S.A., "Evaluation of Connection Flexibility in Cold Formed Steel Racks", Journal of Constructional Steel Research, 2012, Vol. 66, No. 7, pp. 863-872.

[28] Shah, S. N. R., Sulong, N. R., Jumaat, M. Z. and Shariati, M., "State-of-the-art Review on the Design and Performance of Steel Pallet Rack Connections", Engineering Failure Analysis, 2016, Vol. 66, pp. 240-258.

[29] ABAQUS Software Version 6.11 2012. Dassault Systems 